Competing Interests: None declared.

Ethical approval: Not applicable.

Author's contribution: $D C^{1}$ designed and coordinated this research and prepared the manuscript in entirety.

Funding:

None declared.

Acknowledgements: $D C^{1}$ acknowledges project management support of the Center for Regenerative Community Solutions, advice provided by EconoVision and the belp of volunteers.

\title{
Utility of the Blockchain for Climate Mitigation
}

\author{
Delton B. Chen Ph.D ${ }^{1}$ \\ Center for Regenerative Community Solutions, New Jersey, USA
}

Correspondence: deltonchen@crcsolutions.org

Received: 25 March 2018 Accepted: 23 April 2018 Published: 26 April 2018

\begin{abstract}
The blockchain is the enigmatic technology that gave birth to Bitcoin and the cryptocurrency movement. By fate or by good fortune, carbon markets and cryptocurrencies face common problems: a need to find consensus on data, and a need to trade value between distrustful strangers. Could the blockchain ledger enable a consensus on carbon budgets, and deliver value for carbon mitigation services? Could blockchain technologies help to resolve the climate crisis? To answer these questions, we need to examine the opportunities for decentralized ledgers in carbon and energy markets. Here we show that the blockchain offers a unique opportunity to improve accountability in carbon markets and to develop renewable energy micro-grids, but for the blockchain to reach its full potential — to be the game changer - it should be combined with macro-economic policies and macro-prudential regulatory frameworks that can finance a multi-trillion-dollar transition.
\end{abstract}

Keywords: Blockchain, cryptocurrency, climate change, mitigation, carbon offset, carbon credit, decentralised ledger, central bank, macro-economic, macro-prudential

\section{Introduction}

\subsection{Blockchain Ledger}

Since the genesis of Bitcoin (BTC) in January 2009, cryptocurrency trading has grown into a global market that consistently trades US $\$ 10$ to 40 billion-equivalent per day (based on data from [1] for February to March, 2018). Bitcoin and other cryptocurrencies have been popularized for their ability to provide peer-to-peer financial transactions without a bank. Underpinning these cryptocurrencies is the blockchain distributed ledger technology (DLT). In simple terms, the blockchain refers to a digital ledger for people who wish to share and agree on the same information, but who don't want to rely on a centralised authority.

The blockchain ledger relies on a consensus mechanism to address a logical problem called the Byzantine Generals Problem [2] that involves sharing information amongst untrusting actors. The main developer of the blockchain ledger, Satoshi Nakamoto, designed a proof-of-work solution that is Byzantine Fault Tolerant (BFT) [3] [4]. In practice, the likelihood that bad actors could collude to undermine the blockchain ledger is believed negligibly small, and so the ledger and the data it contains are often described as 'immutable'.
Enterprise solutions that are based on blockchain DLTs are attractive to consumers, businesses and institutions because DLTs offer a way to achieve data consensus and accountability across entire operations. The potential advantages of DLTs include reduced administrative costs, reduced fraud and improved data tracking: allowing enterprises to operate more reliably and allowing managers to make informed decisions. One such example is the Australian Securities Exchange (ASX), which is replacing its Clearing House Electronic Subregister System (CHESS) with a new blockchain registry that will operate over a permissioned network [5].

Open-source blockchain standards are being developed to assist and accelerate the mass adoption of blockchain solutions - such as smart contracts that are interoperable with devices and other financial systems. These standards are being developed by various groups, including the Enterprise Ethereum Alliance and the Hyperledger Project.

\subsection{Energy Demand of Distributed Ledgers}

A well-known feature of the Bitcoin network is that its proof-of-work solution forces a deliberate use of computer processing to solve an encrypted puzzle, and 
this is to coordinate consensus amongst computers, to generate new Bitcoins, and to secure the network. This deliberate computer processing creates significant demand for electricity. As of January 2018, the digital mining of Bitcoins consumed more electricity than Portugal (49.8 TWh/yr), and the demand for electricity is rising [6].

Although the electricity consumption of the Bitcoin network is substantial, we should also consider that the Internet consumed 200-300 TWh of electricity in 2017 [7] - and this demand for electricity is also rising steadily. To put this into a broader perspective, the Internet is now comparable to aviation as a source of carbon emissions [8]. This is a stark reminder that the digital economy involves a trade-off with the environment. Driving this trend in energy use is a massive amount of new data being created by new digital devices.

Newer versions of the blockchain consensus mechanism are being developed in an attempt to reduce computer processing and electricity consumption by public DLTs, and one candidate is a proof-ofstake solution. Whatever solutions are adopted for public DLTs, the key challenge is to find an efficient consensus mechanism that can control the scarcity of a cryptocurrency when cryptocurrency mining is needed to finance the network.

The electricity demand of the blockchain consensus mechanism is much less of an issue for commercial solutions that operate on permissioned private networks. For example, Microsoft's Coco Framework replaces the proof-of-work of the Ethereum consortium network with 'trusted enclaves', greatly reducing latency and electricity demand. The Coco Framework also addresses other enterprise issues, such as scalability, data confidentiality and consortium governance. Coco illustrates the great administrative potential of blockchain DLTs over permissioned networks.

\subsection{The Climate Crisis}

Human activities are having a negative impact on the planetary ecosystem, and the climate is especially sensitive to man-made greenhouse gases. The negative consequences of climate change include angry weather, acidic oceans, and rising sea levels [9]. A major risk to the whole climate system is that the Arctic's ice structure is destabilizing with rapid ice melt, warming of seawater, and the mixing of cold Arctic air with warm air from southern latitudes. The Arctic is susceptible to warming feedbacks, including falling albedo with lost sea ice and the release of soil carbon to the atmosphere when permafrost thaws [10]. In February of 2018, daily temperatures in the Arctic remained $20^{\circ} \mathrm{C}$ above the average for longer than a week [11]—which illustrates the dramatic rate of change.

The climate crisis is created by a market failure in carbon emissions, and it persists as a failure to introduce carbon pricing to stay below 1.5 to $2.0^{\circ} \mathrm{C}$ of global warming. These temperature change limits- 1.5 to $2.0^{\circ} \mathrm{C}$-are the ambition of the 2015 Paris Climate Agreement [13], and they are recommended to limit the risks and the impacts of climate change. These limits are needed because ecosystems and civilization are highly sensitive to changes in average surface temperature. For example, most of the world's coral reefs are expected to be 'bleached' dead by $+2.0^{\circ} \mathrm{C}$ of global warming [14]. Professor Veerabhadran Ramanathan, an expert in climate science at the University of California University, warned that climate change could even pose an existential risk to humanity [12].

Nations are working to reduce the carbon intensity of their Gross Domestic Product (GDP), but the 'elephant in the room' is economic growth. Economic growth, as measured by total GDP, increases demand for fossil energy and so growth drives greater carbon emissions [15]. Total GDP grew at an impressive $3.7 \%$ in 2017 [16], and records show that GDP has been growing at roughly 2 to $5 \%$ p.a. since the end of World War II [17]. Adrian Raftery and his colleagues undertook a trend analysis that takes into account economic growth, and they found that our chances of staying under $2.0^{\circ} \mathrm{C}$ are slim, with only a 5-in- 100 likelihood of success [15]. Global warming this century is currently headed towards about $3.2^{\circ} \mathrm{C}$ by 2100 , and there is a $5 \%$ chance of exceeding $4.9^{\circ} \mathrm{C}$, which implies a significant risk of catastrophic climate change [15].

The neoclassical response to climate change is to implement an ideal carbon tax, which is defined by maximum welfare: the point where the tax balances the avoided damages. Some economists advocate hedging against the systemic risks of climate change by further increasing carbon taxes [21] above the ideal tax, and by adjusting investment decisions [20]. To realize the 2015 Paris ambition, the carbon tax would need to be implemented globally, and would need to rise higher than the ideal carbon tax. The High-Level Commission on Carbon Prices-chaired by Joseph Stieglitz and Nicholas Stern-estimates that this higher carbon tax rate would be at least US $\$ 40-80$ per tonne of CO2 by 2020, and US $\$ 50-100$ per tonne of CO2 by 2030 [22]. Professor William Nordhaus, a climate economist at Yale University, wrote in 2016 that staying below $2.5^{\circ} \mathrm{C}$ would require a new global policy [18]. There is clearly a need to introduce stronger carbon pricing into the world economy.

\section{Emerging Blockchain Solutions}

According to the UNFCCC, blockchain technologies can help address the climate crisis by improving 
accountability, transparency and efficiency of the following [23]:

1. Carbon stock-taking for low-carbon projects and the Nationally Determined Contributions (NDCs) of parties to the 2015 Paris Climate Agreement;

2. Carbon offset trading in carbon markets in relation to legal compliance and voluntary offsetting;

3. Peer-to-peer energy trading in decentralized clean energy markets; and

4. Climate finance in terms of old and new business practices.

Another potential blockchain application, which has yet to be widely discussed or addressed, is:

5. the delivery of scalable climate finance for the macro-economic and macro-prudential management of the low-carbon transition.

The success of the 2015 Paris Climate Agreement will depend on functioning carbon and energy marketsbut there are caveats. The main caveat is that marginal improvements in markets will not solve the climate crisis. A major problem is that global energy demand will grow with projected economic growth (refer Section 1.2) and so new economic policies will be needed to limit global fossil fuel consumption and global carbon emissions. To put some meat on the bones of this discussion, we will discuss the above five applications by giving some examples.

\subsection{Carbon Stocktaking}

A curious feature of carbon markets is that the carbon is often portrayed as a commodity. The carbon that is abated from industry or sequestered into forests is not a commodity, because this carbon is not physically transported between buyers and sellers. Carbon markets are mostly trading services, and the service is recorded as a carbon offset/credit. A single carbon offset represents the service of preventing one metric tonne of carbon dioxide equivalent (CO2-e) from entering the atmosphere.

Low-carbon projects receive carbon offsets/credits as revenue for reducing carbon emissions or for sequestering carbon. The carbon amounts should be measured, reported and verified, and then monitored in case of leakage. These administrative processes are vulnerable to freeriding. For example, in 2015 researchers at the Stockholm Environment Institute found that a staggering 0.6 billion metric tonnes of CO2-e was misallocated under the Kyoto Protocol [24]. Interpol has reported on how cartels have exploited the carbon market with fraud and tax evasion scams [25]. Carbon sequestration projects based on forest management face unique technical and political challenges along their supply chain, and indigenous communities who depend on forests for their livelihood are often vulnerable to exploitation and human rights abuses [26].

The diamond trade offers an example of how blockchain technologies could be used to improve accountability. De Beers — the world's largest diamond producer-is inviting traders to register their diamonds on a blockchain ledger to record each diamond's authenticity and ethical origins. The approach requires data verification at each point in the supply chain. A blockchain ledger for carbon stocktaking will similarly require that supply chain is monitored and recorded. IBM is currently working on a blockchain enterprise solution with Energy-Blockchain Labs, and their aim is to streamline China's carbon market. In theory, a similar approach could be used to record the carbon stock take of entire nations-helping to deliver on the Paris Climate Agreement.

\subsection{Carbon Offset Trading}

The compliance market for carbon emissions is dogged by carbon caps below the ambition of the Paris Agreement, and by carbon prices below the social cost of carbon. More stringent laws are needed to raise carbon prices and to reduce carbon emissions. The European Commission has a legislative proposal to tighten the EU emissions trading scheme after 2020 [27], and other governments may follow their lead.

The public may buy carbon offsets in the voluntary carbon market. An online carbon trade exchange developed by CTX (ctxglobal.com) is helpful by ensuring that voluntary purchases are hassle free but selling carbon offsets to the public is like trying to convince the public to voluntarily pay higher taxes. Currently the voluntary carbon market is over-supplied by carbon offsets for this reason.

Some blockchain innovations are occurring in carbon offset markets. One example is Climate Coin Foundation, who plan to use a cryptocurrency — called Climate Coin-to crowd-fund a new platform that will represent carbon offsets with tradable tokens. Another example is a group called Nori, who plan to issue tokens for carbon that will be removed from the atmosphere. No doubt other start-ups will innovate in this space, but their success will depend on a rising price for carbon offsets over the coming years and decades.

\subsection{Electricity Markets}

The decentralization of electricity supply could be one of the most disruptive outcomes of a low-carbon transition. To reduce carbon emissions, commercial 
and residential consumers may prefer to buy their electricity from renewable sources using the town grid or a local micro-grid. Blockchain ledgers can be used to manage the decentralized power sharing, battery storage, feed-in tariffs, and other financial incentives on these grids. Three examples are (1) LO3 Energy's project called Brooklyn Microgrid; (2) Power Ledger's platform for monetizing surplus energy; and (3) Tenne'T's pilot home energy network. Solara is a start-up that will integrate data encryption technology directly into solar PV hardware, and this will improve the reliability of data. This list is by no means exhaustive, and other blockchain applications will likely emerge, especially when electric vehicles put greater demand on the electricity grid as they replace the existing fleet of petrol and diesel vehicles.

\subsection{Green Token Finance}

Green public tokens (cryptocurrencies) are part of a grassroots environmental movement, and they are traded in a living laboratory of people who share common interests. The aim is to crowd fund a project, or to increase trade in a green token. Some examples are Carbon Coin (carboncoin.cc) and Solar Coin (solarcoin. org). Carbon Coin may be supporting a forestry project but its governance is opaque. Solar Coin is issued to citizens who generate electricity with solar PV. These green tokens are promoted with a climate-related mission statement, but the tokens' supply and price are not coupled to carbon metrics, and so it is unclear if they actually help to reduce carbon emissions. Official economic policies may be needed to give green tokens their long-term price stability and environmental purpose. Green public tokens are evidently a nascent innovation that could be better designed to provide more transparency, accountability and tangible results.

\subsection{The New Economy}

The economy is expected to more than double in size between now and 2050 [28], and if this growth is unmanaged and dirty, then it will add significant new demand for coal, oil and natural gas [29]. Dirty growth is a continuation of the growth pattern that began in the 1950's - a pattern that Professor Will Steffen and his colleagues call 'the great acceleration' [30]. Professor Tim Jackson, at Surry University, is adamant that that a new macro-economic policy is needed to provide sustainable growth over the long-term [31].

What kind of macro-economic policy do we need to address the climate crisis? On one hand, there are conventional fiscal policies, such as carbon taxes and cap-and-trade — 'sticks' — and on the other hand there are unconventional green funds, green quantitative easing (QE) and green bond purchases- 'carrots'. It is the author's own opinion that a complete carrotand-stick approach is missing, and that central banks should be involved in a global program of providing monetary stimulus to fill the policy void with scalable climate finance.

A recent report shows that central banks have accumulated about US $\$ 20$ trillion in total assets [32]. This is a significant portion of global wealth, and it suggests that central banks have the capacity to purchase a significant amount of carbon offsets in the voluntary market but missing is a clear mandate for central banks to finance such purchases. New central bank monetary policies could be developed to create more demand for carbon offsets, and these policies should also be used to encourage the private sector to invest in low-carbon projects [33].

To fill the central bank policy void, a Central Bank Digital Currency (CBDC) could be developed, so that the central banks can price climate risk into the global financial system by trading the CBDC with national fiat currencies [33]. Such a CBDC could be developed using distributed ledger technologies (DLT) and permissioned networks between central banks. Central banks were quick to utilize the blockchain to develop CBDCs for inter-banking trade [34], and two examples are Project Ubin [35] and Utility Settlement Coin [36].

With regards to climate risk, the Financial Stability Board for the G20 is conversing with financial industries [37], central banks, and the insurance industry [38]. In April 2018, eight central banks will be meeting in Amsterdam to discuss climate related risk [39]. These activities suggest that central banks are indeed looking for new policies to manage climate risk.

With the right policies, central banks could shape the low-carbon transition by providing macro-prudential governance of climate risk [33]. Such governance should be preemptive because a failure to act preemptively has irreversible long-term consequences. The Fukushima Daiichi nuclear disaster-triggered by a tsunami on 11 March 2011-is a painful reminder of why risk management is important. According to a Bloomberg report [40], the power plant operators, TEPCO, did not respond to a risk assessment concerning extreme tsunami wave heights and advice on emergency power. The take-home message is that certain risks need to be managed preventatively, and the cost of this prevention is analogous to an insurance premium.

\section{Conclusion}

The blockchain is a technology that can help establish consensus within society over information and value, and it will likely play an important role in improving the accountability and transparency of carbon markets and energy markets. It is advised here that the blockchain technology is simply not enough to deliver on the ambitions of the 2015 Paris Climate Agreement, and 
new macro-economic and macro-prudential policies are also needed to manage the economy for rapid decarbonization-at the rate needed to achieve the Paris Agreement. There is a window-of-opportunity for experts in various fields - including central bankers, economists, policy makers, lawyers, scientists and blockchain developers-to collaborate on the solutions for the New Economy.

Humanity has accumulated incredible technical knowledge since the start of the Industrial Age, but the silo effect of people working in their specialized fields poses a problem. Addressing the climate crisis will require new inter-disciplinary collaborations, because a new economy will need a toolbox of radical policies and reliable financial tools that can manage the lowcarbon transition.

\section{References}

[1] [Accessed 20 March 2018$]$ https: / / coinmarketcap. com/

[2] Lamport, L., R. Shostak and M. Pease, (1982). The Byzantine Generals Problem. ACM Transactions on Programming Languages and Systems, 4 (3): 382-401

[37 Nakamoto, S. 2009. Bitcoin: A Peer-to-Peer Electronic Cash System. Retrieved 5 March 2014. Released 24 May, 2009, Satoshi Nakamoto. bttps:/ / bitcoin.org/bitcoin.pdf.

[4] Nakamoto, S. (2008). Private email. The Mail Archive. Thu, 13 Nov 2008 [Accessed 20 March 20187

bttps:/ / wmw.mail-archive.com/cryptography@ metzdowd.com/msg09997.html

[5] [Accessed 20 March 2018$]$ http:/ / fortune.com/2017/12/07/ blockchaintechnology-australian-securities-exchange-asx/

[6] Bitcoin Energy Consumption Index (2018). [Accessed 20 March 2018] https:/ / digiconomist.net/ bitcoin-energy-consumption

77 The Guardian (2017) 'Tsunami of data' could consume one fifth of global electricity by 2025. Guardian Environment Network. [Accessed 20 March 20187

https:/ / www.theguardian.com/ environment/2017/ dec/11/ tsunami-of-data-could-consume-fifth-globalelectricity-by-2025

[8] [Accessed 20 March 2018$]$ https:/ / www.theguardian.com/ environment/2015/ sep/25/server-data-centre-emissions-air-travel-web- google-facebook-greenhouse-gas

[9] Hansen, J., Sato, M., Hearty, P., Ruedy, R., Kelley, M., Masson-Delmotte, V., Russell, G., et al. (2016). Ice melt, sea level rise and superstorms: evidence from paleoclimate data, climate modeling, and modern observations that $2{ }^{\circ} \mathrm{C}$ global warming could be dangerous. Atmos. Chem. Phys., 16:37613812.

[10] Schuur, E. A., McGuire, A. D., Schädel, C., Grosse, G., Harden, J. W., Hayes, D. J., Hugelius, G., Koven, C. D., et al. (2015). Climate change and the permafrost carbon feedback. Nature, 520 (7546): 171-179.

[11] Watts, J. (2018). Arctic warming: scientists alarmed by 'crasy' temperature rises. The Guardian, 28 February 2018.

[Accessed 20 March 2018]

https:/ / www.theguardian.com/ environment/2018/ feb/27/arctic-warming-scientists-alarmed-by-crazytemperature-rises

[12] Xu, Y., and Ramanathan, V. (2017). Well below 2 ${ }^{\circ} \mathrm{C}$ : Mitigation strategies for avoiding dangerous to catastrophic climate changes. PNAS, 114 (39): 10315-10323.

[13] UNFCCC, 2015. Adoption of the Paris Agreement, 21st Conference of the Parties, Paris: United Nations. Report No. FCCC/ CP/2015/L.9/Rev.1

[Accessed 12 September 2017$]$ bttp:/ / unfccc.int/ resource/docs/2015/cop21/ eng/l09r01.pdf.

[14] European Geosciences Union. (2016, April 21). 1.5 C vs 2 C global warming: New study shows why half a degree matters. ScienceDaily. [Accessed March 25, 20187

wnw.sciencedaily.com/ releases/2016/04/160421085218.htm

Raftery, A.E., Zimmer, A., Frierson, D.M., Start\%, $\mathrm{R}$ and Liu, P., 2017. Less than $2^{\circ} \mathrm{C}$ warming by 2100 unlikely. Nature Climate Change (31 July 2017)

[16] IMF (2018) World Economic Outlook. Update, January 2018 [Accessed 11 January 2018] https: / www.imf.org/en/Publications/WEO/ Issues/2018/01/11/ world-economic-outlookupdate-january-2018

[17] World Bank (2018). GDP growth (annual \%). World Bank national accounts data, and OECD National Accounts data files. [Accessed 20 March $2018]$ 
https://data.worldbank.org/indicator/NY.GDP. MKTP.KD.ZG

[18] Nordhaus, W. D., 2016. Projections and uncertainties about climate change in an era of minimal climate policies', Cowels Foundation Discussion Paper No. 2057. New Haven, CT: Yale University.

[19] Aglietta, M., \& Espagne, E., 2016. 'Climate and Finance Systemic Risks, More Than an Analogy? The Climate Fragility Hypothesis', Working Paper CEPII, No 2016-10 - April, pp. 30.

[20] Dietr, S., C. Gollier, and L. Kessler, 2018. The climate beta. Journal of Environmental Economics and Management, 87: 258-274.

[21] Weitrman, M.L. (2010). "Risk-adjusted gamma discounting." Journal of Environmental Economics and Management 60(1): 1-13.

[22] High-Level Commission on Carbon Prices (2017). Report of the High-Level Commission on Carbon Prices. Washington, DC: World Bank.

[23] [Accessed 20 March 2018] http:/ / newsroom.unfccc.int/ climate-action/ howblockechain-technology-could-boost-climate-action/

[24] [Accessed 20 March 2018$]$ bttps:/ / www.sei-international.org/ sei-in-themedial 3207-kyoto-protocols-carbon-credit-schemeincreased-emissions-by-600m-tonnes

[25] [Accessed 20 March 2018$]$ bttps:/ / www.interpol.int/Media/Files/Crimeareas/Environmental-crime/Guide-to-CarbonTrading-Crime-2013

[26] [Accessed 20 March 2018$]$ bttp:/ / wnw.redd-monitor.org/2018/01/25/ buman-rights-and-environmental-organisationsurge-finland-to-stop-funding-the-kenya-forest-servicefollowing-human-rights-abuses-of-indigenous-sengwerpeoplel

[27] [Accessed 20 March 2018] bttp:/ / wnw.europarl.europa.eu/RegData/ etudes/ BRIE/2017/595926/EPRS_ BRI(2017)595926_EN.pdf

[28] [Accessed 20 March 2018] https://www.pwc.com/gx/en/issues/economy/theworld-in-2050.btml

[29] [Accessed 20 March 2018]

http:// news.exxonmobil.com/press-release/ exxonmobil-releases-energy-carbon-summary-and- outlook-energy

[30] [Accessed 20 March 2018]

http://journals.sagepub.com/doi/abs/10.1177/2

053019614564785 ?journalCode $=$ anra

Jackson, T. (2017). Prosperity Without Growth Foundations for the Economy of Tomorrow. London: Routledge.

[Accessed 20 March 2018]

https: / / wmw. zerohedge.com/ news/2018-03-13/ last-breakout

Chen, D. B. (in press). Central Banks and Blockchains: The Case for Managing Climate Risk with a Positive Carbon Price. In: Transforming climate finance and green investment with blockechains. Elsevier. Alastair Marke, Ed., Chapter 9.

Grym, A., Heikekinen, P., Kauko, K., and Takala, K. (2017). Central bank digital currency. Bank of Finland, BoF Economics Review, May 2017, (p.10).

MAS, 2017. The future is bere | Project Ubin: SGD on Distributed Ledger', Monetary Authority of Singapore, Deloitte, $p$ p. 44.

[Accessed 25 August 2017]

bttp:/ / wmw.mas.gov.sg/Singapore-FinancialCentre/Smart-Financial-Centre/Project-Ubin. aspx

[36] [Accessed 20 March 2018] bttps:/ / www.coindesk.com/bsbc-barclays-joinutility-settlement-coin-as-bank-blockchain-test-entersfinal-phasel

[37] [Accessed 20 March 2018] https:/ / www.fsb-tcfd.org/

[387 University of Cambridge Institute for Sustainability Leadership (CISL). (2017). Insurable cities: The ClimateWise Principles Independent Review 2017. Cambridge, UK: Cambridge Institute for Sustainability Leadership. [Accessed 20 March 2018$]$ bttps:/ / www.cisl.cam.ac.uk. business-action/ sustainable-finance/climatewise/principles

[Accessed 20 March 2018] http:/ / www.straitstimes. com/business/banking/ mas-7-other-central-banksform-green-focused-network

[40] [Accessed 20 March 2018$]$ https:/ / www. bloomberg. co.jp/ news/articles/2011-03-16/

LI467Z07SXKY01 